\title{
The Effectiveness of Using Intranet on EFL Female Students' Language Achievement and English language Skills in Mafraq Governorate in Jordan
}

\author{
Siham Jum'ah Hamed Al-mashaqbeh \\ The Ministry of Education Jordan, Directorate of Education of the Al - Mafraq
}

\begin{abstract}
:
This Study examined The Effectiveness of Using Intranet on EFL Female Students' Language Achievement and English language Skills in Mafraq Governorate in Jordan. The current study followed a quasi-experimental design, The number of the participants was (40) Of the tenth grade Female Students' from Umm Alnaam School Secondary in Mafraq Governorate in Jordan. who were allocated randomly into two groups (A, B) In the first group Experimental (A) Female Students' tenth grade learned English Skills by the means of Using Intranet In contrast, the other group Control (B) were taught according to Traditional Method by taught according to the guidelines suggested by the Teacher's Book tenth grade, The results showed that there were differences related to statistical significance at the level of significance $(\alpha=0.05)$ due to the teaching method and the were in favor of the teaching method Using Intranet, The results showed an improvement in the experimental group's English language skills compared to the control group. In the light of the results of the study researcher to include the intranet in the teaching of English skills.

Keywords: Intranet, EFL Students', English Skills, Achievement, Jordan.

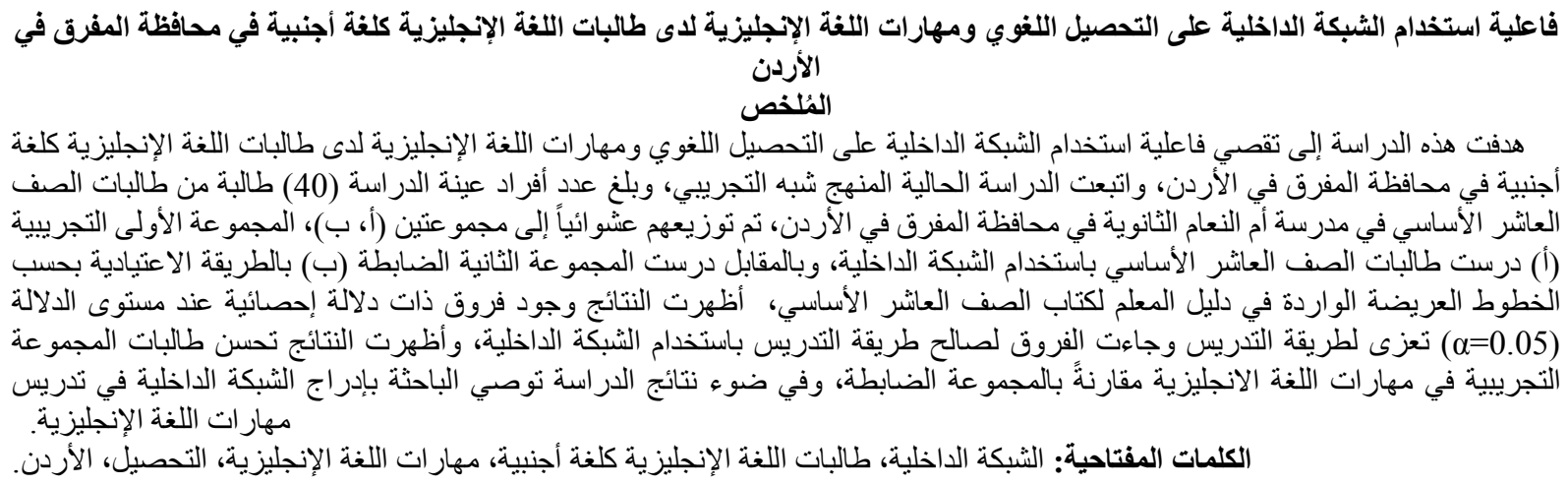

DOI: $10.7176 / \mathrm{JEP} / 10-24-08$

Publication date: August 31st 2019

\section{Introduction:}

English today is believed to be the most influential medium in bridging the global communication. A large proportion of learners in the world study English hard in order to communicate with native speakers or speakers of other languages. Learning a new language involves skills of listening, speaking, reading and writing. Among the four skills, speaking is said to be the most direct way to talk to people, many language teachers consider speaking as the most effective means of gaining a fluent reading knowledge and correct speech as the foundation for good writing. Those teachers also argued that during all one's life one shall probably talk more than one shall write. Therefore, to a language teacher, teaching speaking well is often a valued issue in the field of EFL (Hughes, 2012).

English has become a global language and is used to communicate internationally in areas such as business, science and information technology. To communicate confidently in English a good knowledge of grammar, vocabulary and punctuation is needed. English Language Skills introduces you to the fundamental aspects of English grammar, vocabulary and punctuation and be applied in both written and spoken English. The English Language Skills is a of spoken and written English and become more effective and confident when communicating with other people. and learn about the use of Past, Present and Future tenses, the common mistakes made when using these tenses, and their correct usage. and learn about the word order of a sentence structure and how to turn a sentence into a negative or a question. and English language vocabulary and improve pronunciation skills, English language EFL students who wish to complement their vocabulary and phrases with a greater understanding of grammar. It is also suitable for native English speakers who want to revise their grammar or learn to communicate more effectively(Lightbown, 2016). 
Listening and reading are the receptive skills because learners do not need to produce language, they receive and understand it. These skills are sometimes known as passive skills. The productive skills are speaking and writing because learners are applying these skills in a need to produce language. They are also known as active skills (Serafini, 2014).

The Internet access and web tools change the nature of learning because of its wide variety of the preferred features of flexibility. For example, learners, lecturers, and administrators have a wide range of options to study what they need, at any time they like, from any place they are in, with anybody, in varied settings such as language laboratory, colleges, formal or informal online learning programs etc. (Greenhow, 2012).

Intranet have a significant impact on students' literacy and used as tools for aiding students' academic achievement. Intranet provides chances for learners of English to express themselves and communicate in the target language. Educators and researchers have found that networks are becoming rapidly used in education. (Ahaj \& Banafi, 2011)

Teaching English as a foreign language has recently been receiving a remarkable emphasis owing to the developments taking place in all occupations. New theories, publications and new teaching methods are always introduces to elevate the level of achievement of learner. Precisely, various educational research projects have called attention to the uniqueness of culture and its inseparability from language (Ibrahim, 2016).

Intranet has been shown to play an important role in determining whether a learner persists in a course, the level of engagement shown, the quality of work produced, and the level of achievement attained. Understanding the nature of motivation and the ways in which personal histories, social factors, experiences and circumstances may influence the motivation of learners, therefore, has important practical implications for those involved in online teaching and learning (Schunk et al, 2014).

Lepper and Malone (1987) has found that students language using intranet are often required to be more intrinsically motivated because the learning environment typically relies on intrinsic motivation and the associated characteristics of curiosity and self-regulation to engage learners. In fact, the technology itself is viewed by some as inherently motivating because it provides a number of qualities that are recognized as important in the fostering of intrinsic motivation, namely challenge, curiosity, novelty and fantasy The novelty factor tends to wear off as users become accustomed to the technology (Keller and Suzuki, 2004) and intrinsic motivation can wane. Frustration with technical problems can also reduce intrinsic motivation.

The present study is an attempt to investigate The Effectiveness of Using Intranet on EFL Female Students' Language Achievement and English Skills in Mafraq Governorate in Jordan.

\section{Review of Related Studies}

Hakkarainen (2006) found out that the Research into online Intranet reported that modern language teaching tools environments offer great opportunities for developing writing skills for English language learners.

Palmer (2008) conducted an empirical study in which he surveyed the students' preferences regarding which variety to learn. He generally found that students prefer to learn a spoken variety of Arabic. Nevertheless, in addition to the limited number of respondents the study relies upon, he has not suggested any spoken variety to be taught or as the most suitable one.

Al-Bataineh (2010) explained that the 311 research studies on the effectiveness of technology on students' achievement. Their findings Revealed positive and consistent patterns when students were engaged in Technologyrich environments, including significant gains and achievement in all subject areas, increased achievement in preschool Through high school for both regular and special needs students, and improved attitudes toward learning and increased self-esteem. While controlling for both prior achievement and socio-economic status, fourth-grade students who reported greater frequency of technology use at school to edit papers were likely to have higher total English/ language Arts test scores and higher writing scores on fourth grade test scores on the Massachusetts Comprehensive Assessment System (MCAS) English / language arts test.

Shu (2011) The article describes the integration of Intranet resources as instructional and learning tools in an EFL class. The study examines learners' subjective responses to the use of the Intranet within the context of a research project on American states. Data was collected using observations and surveys including demographic information and student perceptions via subjective-quantitative and qualitative questionnaire items. Analyses consisted of descriptive statistics on the quantitative items and a multi-stage synthesis of the qualitative data including categorical and thematic analysis. With respect to categorical analysis, the excerpts of students' responses were categorized using two codes based on whether they related more to the challenges or advantages of using the Intranet and then under each category they were further subdivided, resulting in twenty subcategories in total. A number of themes were drawn from this data. Learners found the experience generally positive. Negative responses were found to relate to technical problems and information overload. The project stimulated incidental learning. However, information seeking on the Intranet simultaneously engendered both anxiety and excitement in learners. From this study, it could be concluded that computer-learning networks have the potential to empower students in well-designed language learning environments. The Intranet-based language project provided an opportunity to 
enhance students' reading and writing proficiency and to harness their skills in information searching and problemsolving to varying degrees. However, some frustration with the challenges and difficulties in relation to computers and language were found. A computer-mediated learning experience in Language Studies could not be achieved by itself simply by the introduction of the learner to the Intranet technology. Providing scaffolding, both in using Intranet applications and in orienting the learners to the task, is vital to the successful implementation and integration of technology into the curriculum. Implications of using the Intranet in language classrooms is discussed and some suggestions for the direction of future work is outlined.

Ahaj \& Banafi (2011) Digital tools support collaborative learning. The technological collaboration communities provide flexibility in the way users as students work together to achieve their shared goal which is accomplished through varied stages of reflection, evaluation, discussion, negotiation, problem solving. Students use digital tools to improve many of skills such the ability for creative, cooperative problem solving, investigation, network literacy, and citizenship) also, innovation "Knowledge creation is fast becoming the most important sources of new material and intellectual wealth.

Lasagabaster (2015) achievement is a complex psychological construct regarded as one of the determinant factors in successful foreign language learning, which is why it regularly comes to the fore when trying to explain individual differences among language learners. In fact, one of the main objectives of many foreign language teachers in classrooms the world over is to increase student achievement, so that pupils may acquire a good command of English, the current main lingua franca. While many studies have been devoted to the role played by different orientations in this process, this paper focuses on the effect of the approach used in the foreign language classroom. Thus, attention is paid to the relationship between achievement and the language proficiency attained through two different approaches: Content and Language Integrated Learning (CLIL) and English as a Foreign Language (EFL), among 191 secondary school students. The results confirm the benefits of CLIL from both a motivational and a language competence perspective.

Oxford (2016) This digest focuses on teaching integrated skills in the English-as-a-Second/Foreign-Language classroom (ESL/EFL). Segregated-skill instruction is examined and two types of integrated-skills instruction are highlighted: content-based instruction and task-based instruction. The advantages of integrated-skill instruction are discussed, and five steps for teachers to take in integrating language skills in the ESL/EFL classroom are provided.

Maleki \& Zangani (2017) One of the most serious problems that Iranian EFL students face in their field of study is their inability to communicate and handle English after graduating from university. This is due to their weaknesses in general English, which influence their academic success. The intent of the present study was to examine the strength of the relationship between English language proficiency and the academic achievement of Iranian EFL students. Accordingly, the relation between English language proficiency and academic achievement was examined in this study, and a significant connection was found between proficiency and grade point averages of academic achievement. Similarly, the results revealed significant correlation between English language proficiency and achievement in English speaking and writing subjects.

Ayash (2018) explore the effect of using intranet on EFL students' language achievement and motivation. It is also aimed to investigate whether teaching language via using intranet is better than the conventional method of teaching. The population of the study consisted of students in the fifth class in Al Mafraq secondary schools in Jordan who were in rolled in achievement, in the first semester of the academic year 2017/2018. The purposeful sample of the study consisted of 50 students. They were divided in to two groups: group one which comprised the experimental group was supported by intranet while, group two, which was regarded as the control group, created their research via paper and pencil. Intranet was designed with a useful link and learning materials were included. Statistical analyses were used to analyze data from the pre-test, post test scores to answer the question of the study, that is: dose using the intranet to teach students language to secondary schools student improve their language skills compared to the traditional method of teaching? The results showed that students who worked with the intranet had significant gains in their achievement compared with the control group. Additionally, the students who worked with the intranet were more motivated to learn than the other group. In the light of the above finding, it is recommended that the intranet should be incorporated in the teaching of language skills.

\section{Statement of the Problem:}

The researcher's experience and observation inside the foreign language classes, that many schools face difficulties in explain English text and grammar in general and that many Jordanian schools encounter many difficulties in learning English language EFL. In addition, the lack of low achievement in English. The old style learning strategies such as simple note taking rote memorization do not effectively engage students in the active learning.

What is more, our English to Speakers for EFL study English for more twelve years, but they cannot Speaking Skills efficiently. This might be due to the fact that they may not have real opportunities to practice learning Speaking in addition, the researcher believes that teaching by Using Intranet conventional ways may not encourage and help English to Speakers of Other Languages as Arabic to practice the target language naturally in 
the way it is actually used by its Students'.

Accordingly, the researcher ties to investigate The Effectiveness of Using Intranet on EFL Female Students' Language Achievement and English language Skills in Mafraq Governorate in Jordan.

\section{Purpose of the Study:}

The purpose of current study was to The Effectiveness of Using Intranet on EFL Female Students' Language Achievement and English language Skills in Mafraq Governorate in Jordan. This study might be one of the few studies that tackled The Effectiveness of Using Intranet on EFL Female Students' Language Achievement and English language Skills in Mafraq Governorate in Jordan.

\section{Research Questions:}

1. Are they any significant significant differences between the mean scores of the experimental and the control groups' Female students' language achievement at $(\alpha=0.05)$ due to the method of teaching (Using intranet vs. regular instruction)?

2. Are there any statistically significant differences between the mean scores of the experimental group Female students' mastery of each of Female students' English Skills to Using Intranet of learning English?

\section{Research Hypotheses:}

1. There are no statistically significant differences between the experimental and the control group Female students' mean scores in language achievement at $(\alpha=0.05)$ due to the method of teaching (Using intranet vs. regular instruction.

2. There are no any significant differences between the experimental group female students' mastery in English Skills achievement due to using intranet, These achievement include: Reading and Writing Listening and Speaking.

\section{Definition of Terms:}

The following terms will have the associated potential meanings in this study as follows:

Intranet: it is a private network accessible only to an organization's staff. Generally a wide range of information and services from the organization's internal IT systems are available that would not be available to the public from the Internet (Algarabel, \& Dasi, 2001).

EFL Students: It refers to the students who are studying English language as a foreign language in Mafraq Governorate schools in Jordan at tenth grade.

Listening: Listening is a vital component of the oral communication, or the interactive process in which the individual takes the roles of speaker and listener through a verbal and non verbal component (Dash \& Dash, 2007). Speaking: is one of the four language skills Speaking helps students produce those units of meaning in phrases and clauses, not just word by word Speaking is an interactive process of constructing meaning that involves producing, receiving and processing information (Gruber \& Miller, 2006).

Reading: is a cognitive ability which a person is able to use when interacting with the written text (Kose, 2006).

Writing: is a mental work that involves the organization of ideas within topic and structures, word choice, amount of produced writing, as well as lexical and messages to by conveyed (Keshta \& Harb, 2013).

Traditional Method: is the method used by teachers as mentioned in Teachers' Book (Bonk \& Graham, 2006).

Traditional Method: In this study, it refers to teaching of English listening and Speaking and reading and writing and activities and the strategies presented in Teacher's Book tenth grade.

\section{Significance of the Study:}

This study is an attempt to investigate how the of Using Intranet on EFL Students' Language Achievement, and to explore the potential benefits of these devices as a teaching and learning tool. The findings of the study might be officially adopted by the Ministry of Education to use on EFL Students' Language Achievement . By using Intranet on EFL Students' Language Achievement, students' engagement with classes activities will be increased. In addition, teachers may use other technique's in their teaching through using modern technology. Curricula designers may benefit from this study, in the sense that they may use Intranet for students' learning English Skills.

\section{Method and Procedures:}

Design of the Study:

The current study followed a quasi-experimental design in terms of using two experimental groups and two control groups. The independent variable is the Using Intranet instruction. The dependent variable is students' writing performance. The control groups consisted of (20) female students. In contrast, the experimental groups consisted of (20) female students. 


\section{- $\quad$ Participants of the Study}

The participants in the present study consisted female students the tenth grade at a in from Umm Alnaam School Secondary Al-Mafraq In Jordan in the second semester of the academic year 2018-2019. This school was deliberately chosen because the researcher has been working there for the past four years. The number of the participants was (40) female students who were allocated randomly into two groups ( A, B). In the first group (A), female students was taught the learning EFL via Using Intranet. During the sessions of Using Intranet, the participants were given information about Using Intranet; followed by example practices as studied with the teacher. In contrast, the second groups (B) were taught according to the guidelines suggested by the Teacher's Book. All members in the two groups under study were given a writing test the same test were used upon the completion of the training. To obtain valid scores that identify female students' writing performance, clear criteria to assess their works were identified. To qualify this need, the pre-post writing test assessed student' writing in terms of: opinions, magazine articles, letters and writing notes. The design of the study was stated in table 1

Table 1: The Participants of the study

\begin{tabular}{|r|r|r|}
\hline Group & Method of teaching & Number \\
\hline Experimental & Using Intranet & 20 \\
\hline Control & The conventional Method & 20 \\
\hline Total & & 40 \\
\hline
\end{tabular}

From table 1 above, Section A - will consist of 20 female students is assigned as an experimental group who will be taught using (Using Intranet). And Section B - consists of 20 female students which will assign as an a control group will be taught using regular instruction.

\section{The Instructional Program:}

To achieve the purpose of the study, the researcher designed a English language Skills instructional test to Language Achievement and English language Skills (Listening, Speaking, Reading, Writing) as is the program is steered towards enhancing tenth grade female students' English language Skills performance. English language Skills activities in English tenth grade textbook were considered in creating the Using Intranet instructional program.

Certainly, the researcher considered the general guidelines of teaching English language Skills for tenth grade in Mafraq Governorate in Jordan. The pre-test helped in checking the equivalence among groups in terms of writing performance. Later upon the completion of the training, Female students' achievement was assessed by the post-test.

Achievement: of Female students' language In this study, the term is used to refer to the following: Writing, listening, speaking and reading.

Conventional instruction: The use of Traditional methods in delivering the learning material. The term also refers to teaching without the aid of the intranet and using ordinary activities such as paper-pencil method.

\section{The Type of the Program:}

The Using Intranet instructional program started in 11/3/2019 and ended in 11/5/2019 .It is eight weeks within two months. The researcher redesigned the writing material of Module 4 units $(5,6)$ of the Female students' Action pack-10 in order to enhance teachers' use of Using Intranet effectively. Of course, the program was applied only to the assigned experimental groups. Here, the Female students were given three sessions for English language Skills during every two weeks assigned for every lesson; (45) minutes each.

\section{Results and Discussion:}

Ho1: There are no statistically significant differences between the experimental and the control group students' mean scores in language achievement at $(\alpha=0.05)$ due to the method of teaching (Using intranet vs. regular instruction).

Result obtained are presented according to the hypotheses tested as follows: There are no statistically significant differences between the experimental and the control group students' mean scores in language achievement at $(\alpha=0.05)$ due to the method of teaching (Using intranet vs. regular instruction., the result is presented in table 2 below.

Table (2): Means and Standard Deviation of the Experimental and control Groups on the pre-test.

\begin{tabular}{|c|c|c|c|c|c|c|}
\hline Group & Number & Mean & Std. deviation & DF & T & sig \\
\hline Control & 20 & 34.265 & 2.415 & 40 & 0.87 & 0.042 \\
\hline Experimental & 20 & 42.569 & 6.970 & & & \\
\hline
\end{tabular}

From table 2 above reveals that female students' scores for both groups in language achievement were almost equivalent in pre-test before applying the experiment. 
Table (3): Means And Standard Deviation of the Experimental and Control Groups on the pre-posttest.

\begin{tabular}{|c|c|c|c|c|c|c|}
\hline Test & Group & N & Mean & Std. Deviation & T & Sig. \\
\hline \multirow{2}{*}{ Pre test } & Experimental & 20 & 28.201 & 2.915 & \multirow{2}{*}{0.30} & \multirow{2}{*}{0.40} \\
\cline { 2 - 6 } & Control & 20 & 36.320 & 2.109 & & \\
\hline \multirow{2}{*}{ Post test } & Experimental & 20 & 41.58 & 3.80 & \multirow{2}{*}{6.80} & $0.000^{*}$ \\
\cline { 2 - 5 } & Control & 20 & 51.22 & 8.45 & & \\
\hline
\end{tabular}

From table 3 above is a mirror of progress both groups achieved. The experimental group got an increase of 3.80 in their mean score on post-test. And the control group got an increase of 8.45 on the post test. And for the benefit of the experimental group (Using Intranet).

These results go with Ayash (2018) who explore the effect of using intranet on EFL students' language achievement and motivation. It is also aimed to investigate whether teaching language via using intranet is better than the conventional method of teaching in general and on their prosodic competence in particular. These findings are in harmony with Hakkarainen (2006) found out that the Research into online Intranet reported that modern language teaching tools environments offer great opportunities for developing writing skills for English language learners.

Ho2: There are no any significant differences between the experimental group female students' mastery in English Skills achievement due to using intranet, These achievement include: Reading and Writing Listening and Speaking.

Result obtained are no statistically significant differences between the mean scores of the experimental group students' mastery of each of female students' learning Speaking Skills. the result is presented in table 4 below.

For answering this question, ANOVA was used to the experimental group female students score on (English Skills) for pre/post assessment. This step has been done to find out in which skills of English learning have the experimental group female students developed more as a result of Using Intranet.

Table (4) : The post-test results of experimental groups in language skills

\begin{tabular}{|c|c|c|c|c|c|c|}
\hline Skills & group & No. & Mean & Std. Deviation & Value (F) & Sig. \\
\hline Reading & Experimental & 20 & 3.32 & 0.540 & 13.103 & $0.002^{*}$ \\
\hline Writing & Experimental & 20 & 3.36 & 0.582 & 14.214 & $0.003^{*}$ \\
\hline listening & Experimental & 20 & 3.52 & 0.589 & 15.265 & $0.004^{*}$ \\
\hline speaking & Experimental & 20 & 3.62 & 0.511 & 12.658 & $0.001^{*}$ \\
\hline Total & Experimental & $\mathbf{2 0}$ & $\mathbf{3 . 4 6}$ & $\mathbf{0 . 5 5 6}$ & $\mathbf{1 1 . 3 1 0}$ & $\mathbf{0 . 0 0 3 *}$ \\
\hline
\end{tabular}

From table 4 above the According to the results, it was clear that scores of experimental group were statistically higher than those of control group, and the performance of the experimental group on the achievement has improved after practicing language skills via intranet over seven weeks, while there was a little improvement in the performance of the control group in the achievement.

The results are in line with Palmer (2008) conducted an empirical study in which he surveyed the students' preferences regarding which variety to learn. He generally found that students prefer to learn a spoken variety of Arabic. Nevertheless, in addition to the limited number of respondents the study relies upon, he has not suggested any spoken variety to be taught or as the most suitable one. The results revealed that the English to EFL Students' students frequently used paying attention when someone was speaking English, and asking the other person to say again if they did not understand something as their main metacognitive strategies. It was also shown that implementing of Using Intranet materials in English to Speakers of Other EFL Students' class improved the students' attitudes towards language learning. Moreover, the Speaking Skills learning in English to Speakers of Other Languages Students' improved after they English Skills learned materials in classes.

\section{Conclusion:}

The study revealed that Using Intranet in the for learning English EFL Female Students' in from Umm Alnaam School Al-Mafraq In Jordan in English language Skills and Achievement in Jordan because it can help students to be more fluent. Besides, the results of the study showed the new experience motivated students and improved their EFL Students'. More importantly, Using Intranet had positive effectiveness on learning English to EFL Students' learner's vocabulary learning. Moreover, language cannot to be taught without highlighting the fact that language is an ear and a tongue.

\section{Recommendations:}

1. The researcher recommends that the intranet be included in the teaching of language skills.

2. More studies should be done on the effect of Using Intranet in the for learning English EFL Students' language skills, components, competencies . Besides, more researches should be conducted using different, variables, and bigger samples of students .

3. English EFL Students' learner's teachers should know that they cannot teach language English Skills learning without using Intranet. 
4. Training Intranet language teachers and instructors on how to use different Intranet in their classes.

5. English EFL Students' learner's should be encouraged to use Intranet to develop their language skills, components, competencies.

6. Teachers should be more creative in developing new programs teaching English Language in order to make the students eager and engage in the teaching English Language process.

15. References:

Al-Bataineh,A.(2010). The Effect of the Internet on Improving Foreign Language Students'Writing Performance Department of Curricula and Methods of Teaching, College of Education, AL al-Bayt University, Jordan AnNajah Univ. J. of Res. (Humanities), Vol. 24(4), 2010.

Algarabel, H \& Dasí, M.,(2001), The definition of achievement and the construction of tests for its measurement: A review of the main trends Universitat de València, Spain Psicológica, 1(22), 43-66.

Alhaj ,A., \& Banafi,A .(2011).The Impact of Social Networks on EFL Medical Students' Academic Performance at Jazan University. Jazan University (Saudi Arabia), The University of Limerick (Ireland).

Ayash, A. (2018). The Effect of Using Intranet on EFL Students' Language Achievement and Motivation, A magister message that is not published, $\mathrm{Al}$ al-Bayt University, jordan.

Bonk, C. \& Graham, C. (2006). The handbook of blended learning: Global perspectives, local designs. San Francisco CA: Pfeiffer Publisher.

Dash, N. \& Dash, M. (2007). Teaching English As An Additional Languag, New Delhi: Atlantic Publishers and Distributers (P) LTD.

Greenhow, H (2012) Effects of social learning networks on student academic achievement and pro-social behavior in accounting, Journal for educational research, 1 (12), 52-76.

Gruber-Miller, J.(Ed.). (2006). When Dead Tongues Speak: Teaching Beginning Greek and Latin. New York: Oxford University Press, Inc.

Hakkarainen, K. (2006). Design principles and practices for the knowledge-practices laboratory (KP-Lab) project (pp. 603-608). Springer Berlin Heidelberg.5.

Hughes, R. (2002). Teaching and Researching Speaking. London: Pearson Education.

Ibrahem, T. (2016). Using a social networking site for experiential learning: Appropriating, lurking, modeling and community building. The Internet and Higher Education, 13 (4), 188-196.

Keller, J. M., \& Suzuki, K. (2004). Learner motivation and e-learning design: A multination ally validated process. Journal of Educational Media, 29(3), 229-239.

Keshta, A. \& Harb, I. (2013).The Effectiveness of a Blended Learning Program on Developing Palestinian tenth graders' English Writing Skills. Education Journal, 2(6), 208-221.

Kose, N.(2006). Effects of portfolio implementation and assessment critical reading on learner autonomy of EFL students, Education Journal, 3(1), 36-44.

Lasagabaster, D,.(2015). English achievement and student achievement in CLIL and EFL settings, Innovation in Language Learning and Teaching, 1(1), 12-22.

Lepper, M. R., \& Malone, T. W. (1987). Intrinsic motivation and instructional effectiveness in computer-based education. In R. E. Snow \& M. J. Farr (Eds.), Aptitude, learning and instruction (2) 3, 255-286.

Lightbown, P.(2016). How Languages are Learned, $4^{\text {th }}$ edition, Oxford: Oxford University Press.

Maleki, A \& Zangani, E,.(2017). A Survey on the Relationship between English Language Proficiency and the Academic Achievement of Iranian EFL Students, Asian EFL Journal, 1(9), 86-96.

Oxford, R,.(2016). Integrated Skills in the ESL/EFL Classroom. ERIC Digest, ERIC: ED456670, $202-262$.

Serafini, F. (2014). Lessons in comprehension explicit instruction in the reading workshop, Portsmouth, NH: Heinemann.

Shu, Sh,.(2011). Language Learning on the Intranet An Investigation of EFL Learners' Attitudes and Perceptions, Journal of Educational Computing Research, 1(2), 52-67. 